\title{
Cases of two patients undergoing remote CRT device monitoring with fluid retention and algorithm assessment
}

\author{
Jakub Kosma Rokicki ${ }^{1, B-D, F}$, Andrzej Cacko ${ }^{2, A-B, D-E}$, Marcin Grabowski ${ }^{1, A, E}$ \\ A - Research concept and design, B - Collection and/or assembly of data, C - Data analysis and interpretation, \\ D - Writing the article, E - Critical revision of the article, F - Final approval of article \\ 1 First Chair and Department of Cardiology, Medical University of Warsaw \\ 2 Department of Medical Informatics and Telemedicine, Medical University of Warsaw
}

Address for correspondence:

Jakub Kosma Rokicki, First Chair and Department of Cardiology, Medical University of Warsaw email: jakub.rokicki@student.wum.edu.pl

Andrzej Cacko, Department of Medical Informatics and Telemedicine, Medical University of Warsaw email: andrzej.cacko@wum.edu.pl

Marcin Grabowski, First Chair and Department of Cardiology, Medical University of Warsaw email: marcin.grabowski@wum.edu.pl

Received: 09.08.2017

Revised: 26.09 .2017

Accepted: 26.09 .2017

DOI: https://doi.org/10.24255/hbj/78018

\section{Key words:}

cardiac resynchronization therapy, cardiac implantable electronic devices, telemonitoring, fluid retention index

\section{Abstract}

Two patients received a cardiac resynchronization therapy (CRT) device and were remotely monitored with assessment of numerous parameters, including heart rate variability and fluctuation of fluid retention. In both patients alarming signs of heart failure exacerbation occurred in a period of 30 days

\section{Backgrounds}

The progress in the treatment of arrhythmias and heart failure using cardiac implantable electronic devices (CIED) over the last fifty years is enormous. The most sophisticated mechanisms used for such therapy include multifunctional cardiac resynchronisation therapy (CRT) devices. Moreover, the possibility of enabling remote control of patients' cardiac parameters allows physicians to follow patients' cardiac activ-

\section{Case report}

We present two cases of patients (AB and $B G$ ) who were implanted with a Medtronic CRT-D device (Medtronic InSync Sentry and Medtronic Concerto II) in 2009 and 2011, respectively, in primary prevention according to the European Society of Cardiology 2008 Guidelines applicable at that time $^{(2)}$. Subjects (clinical details - see Table 1) - male patients in their seventh decade with a history of ischaemic heart failure, myocardial infarction, and hypertension - were informed preceding the hospitalisation due to the onset of symptoms associated with a failing heart. In those cases, the admission to the hospital could have been predicted by the assessment of data gathered via a telemonitoring system.

ity almost on a daily basis due to the transmission of data via the internet. The annual increase of CRT device implantation (1) due to chronic heart failure creates the need for more effective follow-up care. The main objectives in post-implantation care are prevention of arrhythmic events, lowering the annual hospitalisation rate, and reducing the incidence of heart failure exacerbation.

about the remote monitoring of device function and the way of data storage. Patients were treated appropriately for heart failure with ASA, $\beta$-blockers (carvedilol, bisoprolol), diuretics (furosemide + indapamide, spironolactone), an ACE inhibitor (ramipril), and a statin (atorvastatin) (3). Additionally, due to other comorbidities $\mathrm{AB}$ received eplerenone and amiodarone, and BG received omeprazole and NPH insulin. Ambulatory visits were scheduled every six months, according to the European Society of Cardiology (ESC) guidelines ${ }^{(2)}$. Both 


\begin{tabular}{|c|c|c|}
\hline Clinical feature & $\mathrm{AB}$ & BG \\
\hline Age at implantation & 66 & 60 \\
\hline Comorbidities & $\begin{array}{l}\text { - ischaemic heart failure, } \\
\text { - myocardial infarction } \\
\text { - hypertension } \\
\text { - COPD } \\
\text { - GERD }\end{array}$ & $\begin{array}{l}\text { - ischaemic heart failure, } \\
\text { - myocardial infarction, } \\
\text { - hypertension } \\
\text { - dyslipidaemia } \\
\text { - diabetes mellitus type } 2 \\
\text { - purine metabolism } \\
\text { disorder }\end{array}$ \\
\hline $\begin{array}{l}\text { Medications (daily) } \\
\text { Antiplatelet } \\
\text { B-blocker } \\
\text { diuretic } \\
\text { ACE inhibitor } \\
\text { Statin } \\
\text { Other }\end{array}$ & $\begin{array}{l}\text { - ASA: } 75 \mathrm{mg} \\
\text { - carvedilol } 25 \mathrm{mg} \\
\text { - furosemide } 40 \mathrm{mg}+ \\
\text { indapamide } 1.5 \mathrm{mg} \text {, } \\
\text { - ramipril } 5 \mathrm{mg} \\
\text { - atorvastatin }(20 \mathrm{mg}) \\
\text { - eplerenone }(25 \mathrm{mg}) \\
\text { - amiodarone }(200 \mathrm{mg} \\
\text { 5x/week) }\end{array}$ & $\begin{array}{l}\text { - ASA: } 75 \mathrm{mg} \\
\text { - bisoprolol } 2.5 \mathrm{mg} \\
\text { - spironolactone } 25 \mathrm{mg} \\
\text { - ramipril } 5 \mathrm{mg} \\
\text { - atorvastatin } 40 \mathrm{mg} \\
\text { - omeprazole } 20 \mathrm{mg} \\
\text { - NPH insulin (44 IU/day) }\end{array}$ \\
\hline Presentation & $\begin{array}{l}\text { Dyspnoea } \\
\text { Visual disturbance }\end{array}$ & $\begin{array}{l}\text { Fatigue } \\
\text { Palpitations }\end{array}$ \\
\hline Remote control findings & $\begin{array}{l}\text { OptiVol }>60 \\
\text { HRV }<60 \mathrm{~ms} \\
\mathrm{NHR}>85 / \mathrm{min}\end{array}$ & $\begin{array}{l}\text { Mean } V R A F>90 / \mathrm{min} \\
A F>6 \mathrm{~h} / \text { day } \\
A F \text { burden }>1 \mathrm{~h} / \text { day } \\
\text { Ventricular pacing }<90 \% \\
\mathrm{NHR}>85 / \mathrm{min} \\
\text { Daily activity }<60 \mathrm{~min}\end{array}$ \\
\hline
\end{tabular}

patients agreed on enabling the remote monitoring function; they were included in the program, and since the implantation the data have been stored by the manufacturer. During the observation, the following heart failure indicators were met: the OptiVol index $>60$ in patient AB started 1228 days after implantation, whereas patient $B G$ revealed a mean ventricular rate during atrial fibrillation (VRAF) $>90 / \mathrm{min}$ with $\mathrm{AF}>6 \mathrm{~h} /$ day on day 265 after implantation. Attempts of telephone contact with the patients failed. After 30 days of active heart rhythm changes (patient $\mathrm{AB}: \mathrm{HRV}$ - heart rate variability; patient $\mathrm{BG}$ : VRAF - ventricular rate during atrial fibrillation) they were admitted to hospital. Patient AB presented with dyspnoea and visual disturbances. Patient BG presented with fatigue and palpitations. Both were released home after a prolonged stay (17 and 14 days, respectively) in a stable state with further medical advice.

\section{Discussion}

Numerous variables collected during the operating time of properly functioning cardiac implantable electronic devices include measurements of abnormal autonomics (increased heart rate or diminished heart rate), duration of atrial fibrillation, and thoracic impedance (which can be presented as the OptiVol index). Patients' activity can be effectively used to remotely diagnose worsening of patients' health state ${ }^{(4)}$.

\section{$A B$}

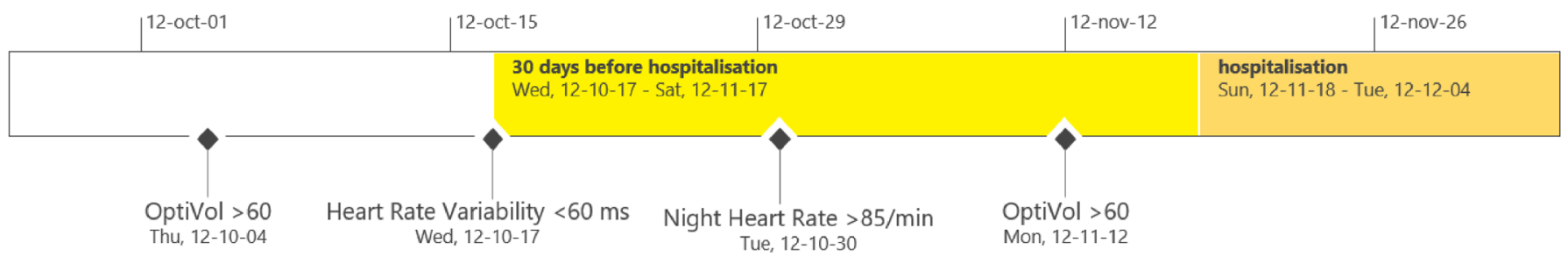

\section{BG}

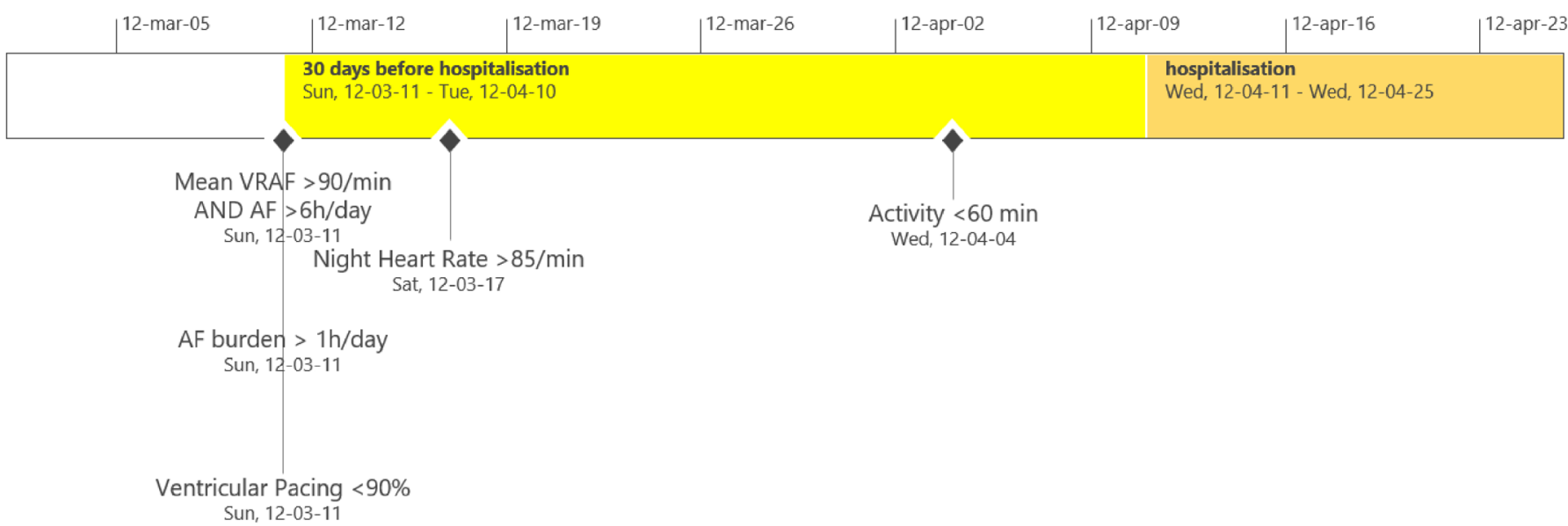


Among many parameters available, thoracic impedance seems to be the most useful factor to predict the decompensation of chronic heart failure and thus unexpected ambulatory visits or acute hospitalisations ${ }^{(5)}$. Other variables measured, namely HRV, nocturnal heart rate, and VRAF, provide additional insight into the clinical state of the patient and need to be included in the overall evaluation ${ }^{(6)}$.

Many algorithms can be used to combine data and support the physician's assessment, followed by a decision including establishing contact with the patient or modification of the treatment. The PARTNERS-HF study presented a way of combining the data with no differences in the risk subgroups ${ }^{(5)}$. A recent study by Boehmer et al. constructed a new model in the MultiSENSE trial that evaluated the symptoms of heart failure with greater sensitivity ${ }^{(4)}$.

A clinical trial conducted by Domenichini et al. showed that alert-guided care does not prevent hospitalisation but can help In supporting the patient's well-being and self-assessed quality of life $\mathrm{e}^{(7)}$. Moreover, the cost-effectiveness impact on the healthcare system may be beneficial due to implementation of such a solution, where the physician's decisions will be supported by algorithmic remotely gathered findings, but this view will soon be verified according to the rules of evidence-based medicine ${ }^{(8)}$.

It is important to take into account that today modern algorithms and systems allow physicians to predict with high accuracy that an owner of a CRT device will soon become (in 30 days) a patient in their (or another) department ${ }^{(5,8)}$. To understand the gravity of this fact, one need only consider how many preventive actions can be undertaken during those 30 days to avoid such an event.

New devices are currently being invented to provide remote fluid accumulation monitoring with no invasive therapy such as implantable cardiac devices and may be helpful to provide such data to physicians in the future. ${ }^{(9)}$

\section{Conclusions}

Multiple data gathered from patients implanted with a CRT device with remote monitoring may with satisfactory accuracy predict worsening of their health state and subsequent hospitalisation in the following month; hence prevention of hospitalisation can occur remotely in the patient's home. It is believed that changes in the monitoring centre mode of work and the insurance funding scheme have the potential to lower the long-term cost of patients' healthcare, which will soon be verified.

\section{References}

1. Raatikainen MJ, Arnar DO, Zeppenfeld K, et al. Statistics on the use of cardiac electronic devices and electrophysiological procedures in the European Society of Cardiology countries: 2014 report from the European Heart Rhythm Association. Europace, 2015; 17 Suppl 1: i1-75. doi: 10.1093/europace/euu300.

2. Dickstein K, Cohen-Solal A, Filippatos G, et al. ESC guidelines for the diagnosis and treatment of acute and chronic heart failure 2008: the Task Force for the diagnosis and treatment of acute and chronic heart failure 2008 of the European Society of Cardiology. Developed in collaboration with the Heart Failure Association of the ESC (HFA) and endorsed by the European Society of Intensive Care Medicine (ESICM). Eur J Heart Fail, 2008; 10: 933-989. doi: 10.1016/j.ejheart.2008.08.005.

3. Ponikowski P, Voors AA, Anker SD, et al. 2016 ESC Guidelines for the diagnosis and treatment of acute and chronic heart failure. The Task Force for the diagnosis and treatment of acute and chronic heart failure of the European Society of Cardiology (ESC) Developed with the special contribution of the Heart Failure Association (HFA) of the ESC. European Heart Journal, 2016; 37: 2129-2200. doi: 10.1093/eurheartj/ehw128.

4. Boehmer JP, Hariharan R, Devecchi FG, et al. A multisensor algorithm predicts heart failure events in patients with implanted devices. JACC: Heart Failure, 2017; 5: 216-225. doi: http://dx.doi.org/10.1016/j. jchf.2016.12.011.

5. Whellan DJ, Ousdigian KT, Al-Khatib SM, et al. Combined heart failure device diagnostics identify patients at higher risk of subsequent heart failure hospitalizations. Journal of the American College of Cardiology, 2010; 55: 1803-1810. doi: http://dx.doi.org/10.1016/j. jacc.2009.11.089.

6. Braunschweig F, Mortensen PT, Gras D, et al. Monitoring of physical activity and heart rate variability in patients with chronic heart failure using cardiac resynchronization devices. American Journal of Cardiology; 95: 1104-1107. doi: 10.1016/j.amjcard.2004.12.069.

7. Domenichini G, Rahneva T, Diab IG, et al. The lung impedance monitoring in treatment of chronic heart failure (the LIMIT-CHF study). EP Europace, 2016; 18: 428-435. doi: 10.1093/europace/euv293.

8. Hawkins NM, Virani SA, Sperrin M, Buchan IE, McMurray JJV, Krahn AD. Predicting heart failure decompensation using cardiac implantable electronic devices: a review of practices and challenges. European Journal of Heart Failure, 2016; 18: 977-986. doi: 10.1002/ejhf.458.

9. Silva R, Cardoso J, Sousa F. Measuring impedance in congestive heart failure. Stud Health Technol Inform, 2017; 237: 157-162. doi. 